\title{
ANALISIS RANTAI PEMASARAN IKAN DI TEMPAT PELELANGAN IKAN (TPI) KARANGANTU SERANG, BANTEN
}

\author{
Muhammad Reza Rozaqi, Ediyanto \\ Fakultas Perikanan dan Ilmu Kelautan Universitas Satya Negara Indonesia \\ Jln, Arteri Pondok Indah No. 11 Jakarta 12240 \\ E-mail: Rezarozaqi.mm@gmail.com
}

\begin{abstract}
:
The rapid development of fishery products in Indonesia as well as a large contribution to Gross Domestic Product (GDP) especially from sea fishing business, unfortunately still not recognized. The scale of small-scale enterprises and the fisherman's status, mostly fishermen who are related to the fisherman's fish marketing system as a producer, have a weak position compared to the trader or industry as the buyer. This study aims to 1) to know Margin Analysis and Fisherman Analysis Share chain of fish marketing to fishermen and retailers; 2) to know the institutional role involved in the marketing of fishery products in TPI Karangantu. This research was conducted from September to October 2016 at TPI Karangantu Serang Banten. The research method used by collecting from primary data and secondary data with descriptive analysis, marketing margin analysis and Fisherman Share analysis. The results of the calculation of Marketing margin analysis and Fisherman Share analysis from fishermen to retailers in September - November were Bullfish Rp.3.999 and 84\%, Bloated Fish Rp.5.483 and 82\%, Japuh Fish Rp.2.164 and 75\%, Lemuru Fish Rp. 2.444 and 89\%, Fish Fly Rp. 2.487 and 90\%, Mackerel Fish Rp. 5,063 and 91\%, Anchovy Rp. 2,461 and $81 \%$.
\end{abstract}

KEYWORDS: TPI Karangantu, Rantai Pemasaran, Analisis

\section{PENDAHULUAN}

Pesatnya perkembangan hasil produksi perikanan di Indonesia serta sumbangannya yang besar terhadap Produk Domestik Bruto (PDB) khususnya dari usaha penangkapan ikan laut, sayangnya masih belum diikuti dengan peningkatan kesejahteraan nelayan. Pola perdagangan hasil perikanan yang berlangsung selama ini mulai dari nelayan selaku produsen sampai ke tangan konsumen dapat dikenali adanya ketidakefesianan sistem pemasaran yang ditandai dengan adanya disparitas harga dan perolehan keuntungan usaha antara nelayan dengan pedagang (Koeshandoko, 2006).

Produksi yang baik akan sia-sia karena harga pasar yang rendah, sehingga tingginya produksi tidak mutlak memberikan keuntungan yang tinggi tanpa pemasaran yang baik dan efisien. Secara umum pemasaran dapat diartikan sebagai segala kegiatan yang dilakukan oleh berbagai perantara dengan berbagai macam cara 
untuk menyampaikan hasil produksi, yaitu ikan laut segar, dari produsen ke konsumen akhir (Hanafiah dan Saefudin, 2006).

Besarnya keuntungan pemasaran dan biaya pemasaran di tingkat perantara merupakan komponen dalam pembentukan harga akhir (harga eceran) ditingkat konsumen. Hal ini akan berpengaruh pada harga ditingkat produsen, bahkan dapat menekan harga ditingkat produsen karena daya beli sebagian konsumen masih terbatas (Noviana, 2003).

Secara umum masyarakat nelayan tangkap dibedakan atas dua golongan yaitu nelayan tetap dan nelayan sambilan, kehidupan masyarakat nelayan masih sederhana, terlihat dari hasil rata-rata tangkapan nelayan hanya untuk memenuhi kebutuhan sehari-hari. Hal ini disebabkan oleh alat tangkap dan armada penangkapan yang dimiliki oleh para nelayan hanya mampu melakukan penangkapan pada daerah sekitarnya. Produksi perikanan di (PPN) Karangantu yang dominan tertangkap yaitu ikan kurisi, tongkol, teri, lemuru, udang, cumi-cumi, sotong, pari, bondolan, kembung, Japuh, layang, kembung, tenggiri dan kuniran .

Nelayan di PPN Karangantu memberikan hasil tangkapannya langsung kepada tengkulak setelah melaut dan oleh tengkulak hasil tangkapan tersebut langsung dipasarkan kepada konsumen, dari keuntungan pemasaran ikan tersebut nelayan mendapatkan hasil penjualan lebih banyak dari tengkulak.

Secara umum kegiatan saluran distribusi ikan hasil tangkapan nelayan umumnya dilakukan di tempat pelelangan ikan (TPI), namun di TPI Karangantu yang memiliki luas $\pm 500 \mathrm{~m}$ TPI tersebut kurang berjalan dengan baik dikarenakan kurang luasnya tempat lelang dan juga sistem lelang yang tidak berjalan dan juga kurang tegas petugas TPI Karangantu sehingga banyak nelayan yang menjual hasil tangkapanya ke tengkulak hanya sebagian nelayan yang menurunkan hasil tangkapannya untuk ditimbang di TPI Karangantu.

\section{MATERI DAN METODE}

Penelitian dengan judul "Analisis Rantai Pemasaran Ikan di Tempat Pelelangan Ikan (TPI) Karangantu Serang, Banten” telah dilaksanakan pada Bulan September - November 2016 di TPI Karangantu.

Jenis data yang dikumpulkan dalam penelitian ini terdiri dari data primer dan data sekunder. Data primer yaitu data yang diambil secara langsung yaitu dengan metode wawancara terhadap nelayan dan pedagang perantara. Sedangkan data sekunder adalah data yang diperoleh dari pihak-pihak ataupun instansi-instansi seperti TPI Karangantu.

\section{METODOLOGI}

Metode Penelitian yang dilakukan menggunakan metode penelitian studi kasus. Penelitian studi kasus harus dilakukan secara dialektik antara bagian dan keseluruhan. Maksudnya, untuk memahami aspek tertentu perlu diperoleh gambaran umum tentang aspek itu. Sebaliknya, untuk memperoleh gambaran umum diperlukan pemahaman bagian-bagian khusus secara mendalam.

Untuk memperoleh pengetahuan secara mendalam, data studi kasus dapat diperoleh tidak saja dari kasus yang diteliti, tetapi juga dari semua pihak yang 
mengetahui dan mengenal kasus tersebut dengan baik. Data atau informasi bisa dari banyak sumber, tetapi perlu dibatasi hanya pada kasus yang diteliti.

Dalam penelitian ini pengambilan data dilakukan dengan cara, wawancara langsung dengan nelayan dan lembaga pemasaran (responden) berdasarkan pertanyaan sesuai dengan data yang dibutuhkan, mencatat dan mengumpulkan data dari responden dan instansi yang terkait dengan penelitian ini, melakukan observasi yaitu mengadakan pengamatan langsung di lapangan pada setiap obyek dan permasalahan yang diteliti untuk melengkapi data primer dan data sekunder.

\section{ANALISIS DATA}

Analisis deskriptif uraian atau usaha untuk mengetahui arti suatu keadaan data atau bahan keterangan mengenai suatu keadaan dan diselidiki hubungannya satu sama lain. Tujuan analisis deskriptif adalah untuk menyederhanakan data-data ke dalam bentuk yang lebih mudah dibaca dan diinterpretasi.

Untuk mengetahui besarnya margin yang diperoleh disetiap lembaga lembaga pemasaran, maka akan dilakukan pengujian dengan menggunakan rumus margin pemasaran yaitu sebagai berikut (Hanafiah dan Saefuddin, 2006).

Analisis ini digunakan untuk membandingkan harga yang diterima produsen atau petani dengan harga yang dibayarkan oleh konsumen akhir bisa disebut dengan Fisherman Share (Hanafiah dan Saefuddin, 2006). Fisherman Share berhubungan negatif dengan margin pemasaran, semakin tinggi pemasaran maka bagian yang akan diperoleh produsen atau petani semakin rendah.

\section{HASIL DAN PEMBAHASAN}

Selama penelitian diperoleh sampel harga dari 16 nelayan dan 25 pedagang pengecer dapat dilihat pada Tabel 4.

\begin{tabular}{|l|r|r|r|r|r|r|}
\hline \multirow{2}{*}{\multicolumn{1}{c|}{ Bulan }} & \multicolumn{6}{|c|}{ Harga Ikan $(\mathrm{Rp} / \mathrm{Kg})$} \\
\cline { 2 - 7 } \multicolumn{1}{|c|}{ Jenis Ikan } & \multicolumn{2}{|c|}{ September } & \multicolumn{2}{c|}{ Oktober } & \multicolumn{2}{c|}{ November } \\
\hline Ikan Tongkol & 19.357 & Pengecer & Nelayan & Pengecer & Nelayan & Pengecer \\
\hline Ikan Kembung & 23.615 & 28.450 & 20.429 & 24.500 & 21.333 & 25.167 \\
\hline Ikan Jepuh & 5.625 & 7.647 & 6.417 & 8.471 & 7.000 & 9.417 \\
\hline Ikan Lemuru & 18.667 & 21.000 & 20.000 & 22.000 & 21.000 & 24.000 \\
\hline Ikan Layang & 20.250 & 22.300 & 21.273 & 23.615 & 22.136 & 25.231 \\
\hline Ikan Tenggiri & 47.571 & 51.217 & 48.643 & 53.636 & 50.455 & 57.000 \\
\hline Ikan Teri & 9.267 & 11.350 & 10.636 & 12.947 & 11.385 & 14.375 \\
\hline
\end{tabular}

Dapat disimpulkan kenaikan harga ikan pada setiap bulannya sebesar Rp 1.000 - Rp 2.000. Harga ikan pada bulan September-November mengalami kenaikan dikarena pada bulan tersebut jarang nelayan yang melaut disebabkan oleh faktor musim pada bulan tersebut.

Tabel 5. Margin Pemasaran Bulan September-November Tahun 2016.

\begin{tabular}{|l|l|l|l|}
\hline No & Komoditas & Margin Pemasaran (Rp) & Rata-rata \\
\hline
\end{tabular}




\begin{tabular}{|r|l|r|r|r|r|}
\hline & & \multicolumn{1}{|c|}{ September } & \multicolumn{1}{c|}{ Oktober } & \multicolumn{1}{c|}{ November } & \multicolumn{1}{c|}{$(\mathrm{Rp})$} \\
\hline 1 & Ikan Tongkol & 4.093 & 4.071 & 3.834 & 3.999 \\
\hline 2 & Ikan Kembung & 4.840 & 5.150 & 6.458 & 5.483 \\
\hline 3 & Ikan Japuh & 2.022 & 2.054 & 2.417 & 2.164 \\
\hline 4 & Ikan Lemuru & 2.333 & 2.000 & 3.000 & 2.444 \\
\hline 5 & Ikan Layang & 2.050 & 2.342 & 3.068 & 2.487 \\
\hline 6 & Ikan Tenggiri & 3.646 & 4.993 & 6.550 & 5.063 \\
\hline 7 & Ikan Teri & 2.083 & 2.311 & 2.990 & 2.461 \\
\hline
\end{tabular}

Rata-rata margin pemasaran Ikan Tongkol pada bulan September - November

2016 adalah Ikan Tongkol Rp. 3.999, Ikan Kembung Rp. 5.483, Ikan Japuh Rp. 2.164, Ikan Lemuru Rp. 2.444, Ikan Layang Rp. 2.487, Ikan Tenggiri Rp. 5.026, Ikan Teri Rp. 2.461.

Tabel 6. Hasil Penghitungan Fisherman Share Bulan September-November Tahun 2016.

\begin{tabular}{|r|l|r|r|r|r|}
\hline \multirow{2}{*}{ No } & \multirow{2}{*}{ Komoditas } & \multicolumn{3}{|c|}{ Fisherman Share (\%) } & \multirow{2}{*}{$\begin{array}{c}\text { Rata - rata } \\
(\%)\end{array}$} \\
\cline { 3 - 5 } & & September & Oktober & November & 84 \\
\hline 1 & Ikan Tongkol & 83 & 83 & 85 & 82 \\
\hline 2 & Ikan Kembung & 83 & 83 & 80 & 75 \\
\hline 3 & Ikan Japuh & 74 & 76 & 74 & 89 \\
\hline 4 & Ikan Lemuru & 89 & 91 & 88 & 90 \\
\hline 5 & Ikan Layang & 91 & 90 & 88 & 91 \\
\hline 6 & Ikan Tenggiri & 93 & 91 & 89 & 81 \\
\hline 7 & Ikan Teri & 82 & 82 & 79 & (2) \\
\hline
\end{tabular}

Berdasarkan perhitungan analsisi Fisherman Share pada Tabel 6 dapat dilihat efisiensi masing-masing menunjukan rata-rata Fisherman Share dari bulan September-November sudah efisien karena pemasaran dari nelayan sampai pedagang pengecer sudah diatas $50 \%$.

Tabel 7. Data Produksi Hasil Tangkapan Bulan September-November Tahun 2016

\begin{tabular}{|c|l|c|c|c|}
\hline \multirow{2}{*}{ No } & \multirow{2}{*}{ Jenis Ikan } & \multicolumn{3}{|c|}{ Produksi (Kg) } \\
\cline { 3 - 5 } & & September & Oktober & November \\
\hline 1 & Ikan Tongkol & 1.014 & 3.598 & 1.096 \\
\hline 2 & Ikan Kembung & 3.936 & 3.215 & 6.289 \\
\hline 3 & Ikan Japuh & 1.842 & 1.694 & 3.653 \\
\hline 4 & Ikan Lemuru & 85 & 104 & 185 \\
\hline 5 & Ikan Layang & 90 & 106 & 655 \\
\hline 6 & Ikan Tenggiri & 488 & 1.547 & 2.120 \\
\hline 7 & Ikan Teri & 47.468 & 14.805 & 32.983 \\
\hline
\end{tabular}

Sumber : PPN Karangantu 2016

Pada Tabel 7 dapat dilihat Ikan Tenggiri lebih banyak hasil tangkapannya dibandingkan dengan Ikan Lemuru yang hasil tangkapannya lebih sedikit dapat 
disimpulkan pada Ikan Tenggiri permintaan dipasar lebih banyak dan dapat memenuhi kebutuhan pasar sedangkan pada Ikan Lemuru kurang memenuhi kebutuhan pasar dan Ikan Lemuru kurang peminatnya.

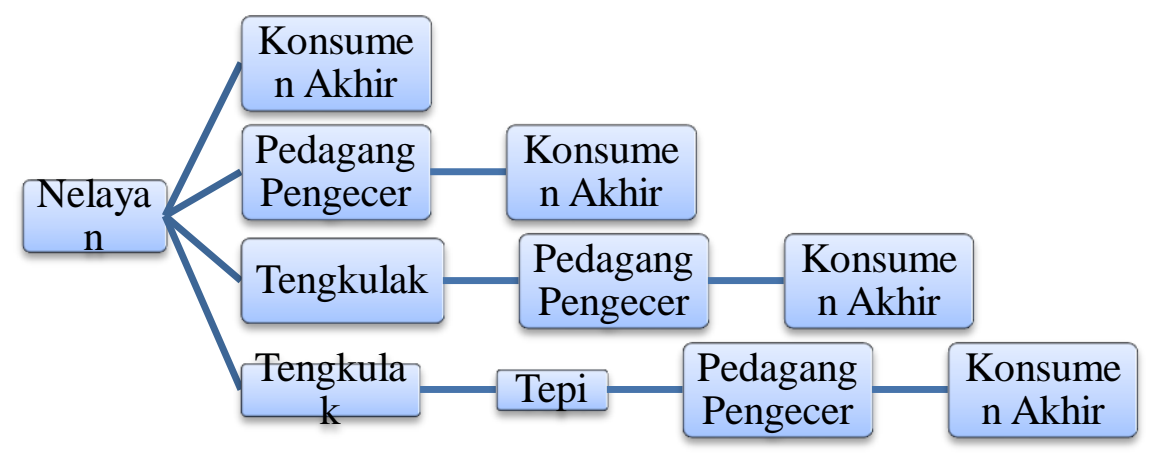

Gambar 9. Rantai Pemasaran Ikan di TPI Karangantu

Gambar 9 di atas menerangkan bahwa pada alur pemasaran I nelayan menjual hasil tangkapannya ke konsumen akhir. Alur pemasaran II nelayan menjual hasil tangkapannya kepada pengecer setelah itu pengecer menjual kepada konsumen akhir. Alur pemasaran III nelayan menjual hasil tangkapannya melalui tengkulak setelah itu tengkulak menjual kepada pedagang pengecer dan pedagang pengecer menjual kepada konsumen akhir. Alur pemasaran IV nelayan menjual hasli tangkapannya kepada tengkulak setelah itu tengkulak menggunakan jasa tepi untuk memasarkan ikan kepada pedagang pengecer dan pedagang pengecer menjual ke konsumen akhir.

\section{PPN Karangantu}

Peran PPN di TPI Karangantu berfungsi dalam mendukung setiap kegiatan yang berhubungan dengan sumberdaya ikan, seperti mencatat berapa banyak kapal yang masuk dan keluar di pelabuhan, mendata setiap jenis hasil tangkapan yang didapat oleh nelayan dan mengawasi setiap kegiatan di TPI Karangantu.

\section{TPI Karangantu}

TPI merupakan pasar yang biasanya terletak di dalam pelabuhan atau pangkalan pendaratan ikan dan tempat tersebut terjadi transaksi penjualan ikan atau hasisl laut yang baik secara lelang maupun tidak. Biasanya TPI dikoordinasi oleh Dinas Perikanan, Koperasi atau Pemerintahan Daerah.

Pelelangan ikan merupakan suatu kegiatan dimana penjual dan pembeli bertemu dalam suatu tempat (gedung TPI), didalamnya terjadi proses tawar menawar harga ikan sehingga diperoleh harga yang mereka sepakati bersama. Dalam proses tawar menawar, kualitas ikan akan memegang peran penting dalam penentuan harga. Pembeli akan memberikan penawaran yang cukup tinggi terhadap ikan yang berkualitas lebih baik meskupun pada awalnya nelayan yang akan mengajukan harga terlebih dahulu melalui petugas lelang. 
Fungsi TPI antara lain adalah : memperlancar kegiatan pemasaran ikan dengan sistem lelang, mempermudah pembinaan mutu ikan hasil tangkapan nelayan, mempermudah pengumpulan data statistik.

\section{Nelayan}

Nelayan yang berada di wilayah PPN Karangantu adalah nelayan tradisional yang digolongkan menjadi nelayan pribumi maupun nelayan pendatang. Nelayan pribumi berasal dari Kota Serang dan nelayan pendatang berasal dari Lampung, Indramayu, Cirebon dan Brebes.

Hasil pengamatan dan wawancara yang dilakukan dengan nelayan PPN Karangantu diketahui bahwa kegiatan perikanan di Karangantu secara umum merupakan perikanan tangkap dengan menggunakan berbagai jenis alat tangkap dan armada penangkapan. Jumlah nelayan yang ada di PPN Karangantu pada tahun 2016 secara keseluruhan berjumlah 1.822 .

\section{Tengkulak}

Tengkulak dalam pemasaran ikan di Karangantu terbagi menjadi 2 yaitu tengkulak yang menjual hasil tangkapan dari nelayan dengan sistem saling membutuhkan satu sama lainnya seperti tengkulak membutuhkan biaya operasional dalam proses penangkapan dan tengkulak butuh hasil tangkapan untuk dijual, selain itu juga ada tengkulak yang hanya menjual hasil tangkapan nelayan.

Data yang diperoleh dari hasil penelitian di TPI Karangantu dari 16 nelayan 10 diantaranya mendapat penghasilan dari tengkulak, sedangkan dari 6 nelayan mendapatkan penghasilan dari tengkulak yang membiayai operasional dari nelayan, dan sisanya 4 nelayan mendapatkan penghasilan dari tengkulak yang menjual hasil tangkapannya dan 6 nelayan menjual hasil tangkapannya ke pedagang pengecer dan konsumen akhir.

\section{Pedagang Perantara (Tepi)}

Pedagang perantara (tepi) merupakan pedagang perantara yang memiliki tugas sebagai penghubung tengkulak dalam memasarkan ikan dan mempertemukan konsumen kepada tengkulak dan ada juga perantara yang mempertemukan tengkulak kepada pedagang pengecer. Data yang diperoleh selama penelitian harga jual ikan dari tepi ada yang lebih mahal dari tengkulak dan ada juga yang lebih murah dari tengkulak.

\section{Pedagang Pengecer}

Selama penelitian pedagang pengecer di TPI Karangantu umumnya berada di pasar ikan bersebelahan dengan TPI, dalam hal ini pedagang pengecer membeli ikan ada yang langsung melalui nelayan dan ada juga yang melalui tengkulak dan pedagang perantara (tepi) dan menjualnya kembali dalam bentuk yang sama tanpa ada perlakuan apapun hanya saja ada proses pengawetan kembali dengan 
menggunakan es balok agar ikan dalam kondisi segar dan tidak mudah membusuk. Fungsi pemasaran pedagang pengecer adalah menyalurkan ikan kepada konsumen.

\section{KESIMPULAN DAN SARAN}

Berdasarkan penelitian analisis rantai pemasaran ikan dapat disimpulkan sebagai berikut: 1) Perhitungan rata-rata Analisis Margin pemasaran ikan dan Analisis Fisherman Share dari nelayan sampai pedagang pengecer pada bulan September sampai November yaitu pada Ikan Tongkol dengan margin pemasaran Rp. 3.999 dan Fisherman Share 84 \% Ikan Kembung dengan margin pemasaran Rp. 5.483 Fisherman Share 82\%, Ikan Japuh dengan margin pemasaran Rp. 2.164 dengan Fisherman Share 75\%, Ikan Lemuru dengan margin pemasaran Rp. 2.444 dan Fisherman Share 89\%, Ikan Layang dengan margin pemasaran Rp. 2.487 dan Fisherman Share 90\%, Ikan tenggiri dengan margin pemasaran Rp. 5.063 dan Fisherman Share 91\%, Ikan Teri dengan harga Rp. 2.461 dan Fisherman Share 81\%. 2) Fungsi PPN Karangantu seperti mencatat berapa banyak kapal yang masuk dan keluar di pelabuhan, mendata setiap jenis hasil tangkapan yang didapat oleh nelayan dan mengawasi setiap kegiatan di TPI Karangantu. Lembaga yang terlibat dalam hasil perikanan tangkap di TPI Karangantu yaitu nelayan, tengkulak, pedagang perantara (tepi), pedagang pengecer dan konsumen akhir.

Saran dari hasil Penelitian ini adalah perlu adanya peluasan dan perbaikan fasilitas tempat pelelangan ikan sehingga banyak nelayan yang menurunkan hasil tangkapannya di TPI Karangantu dan lebih tegasnya petugas TPI Karangantu sehingga nelayan tidak menjual hasil tangkapannya melalui tengkulak.

\section{Daftar pustaka}

Hanafiah, A.M dan A.M. Saefudin. 2006. Tata Niaga Hasil Perikanan. UI Press. Jakarta.

Kantor Pelabuhan Perikanan Nusantara Karangantu, 2015. Laporan Tahunan Statistik PPN Karangantu.

Koeshandoko, H. 2006. Kajian Sistem Pemasaran dan Keterpaduan Pasar Ikan Laut Segar di Pangkalan Pendaratan Ikan Bajomulya, Juwana Kabupaten Pati, JawaTimur.

Noviana, C .D. 2003 Analisis Ikan Laut Segar di Kabupaten Cilacap. Fakultas Ekonomi Universitas Sebelas Maret. Surakarta. 